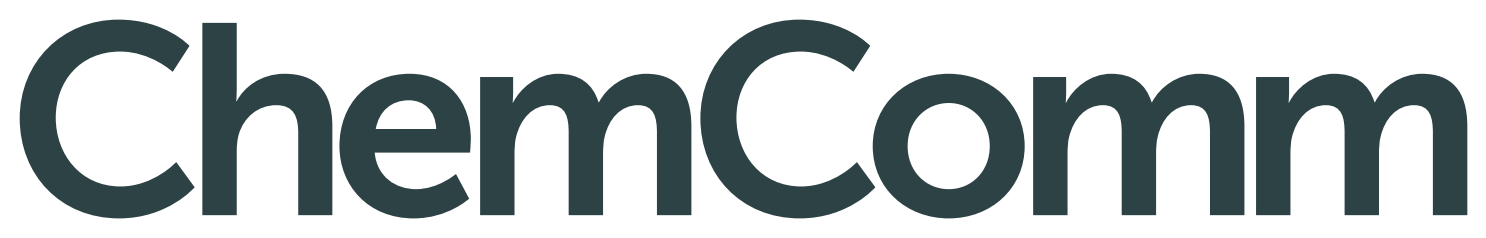

Chemical Communications rsc.li/chemcomm
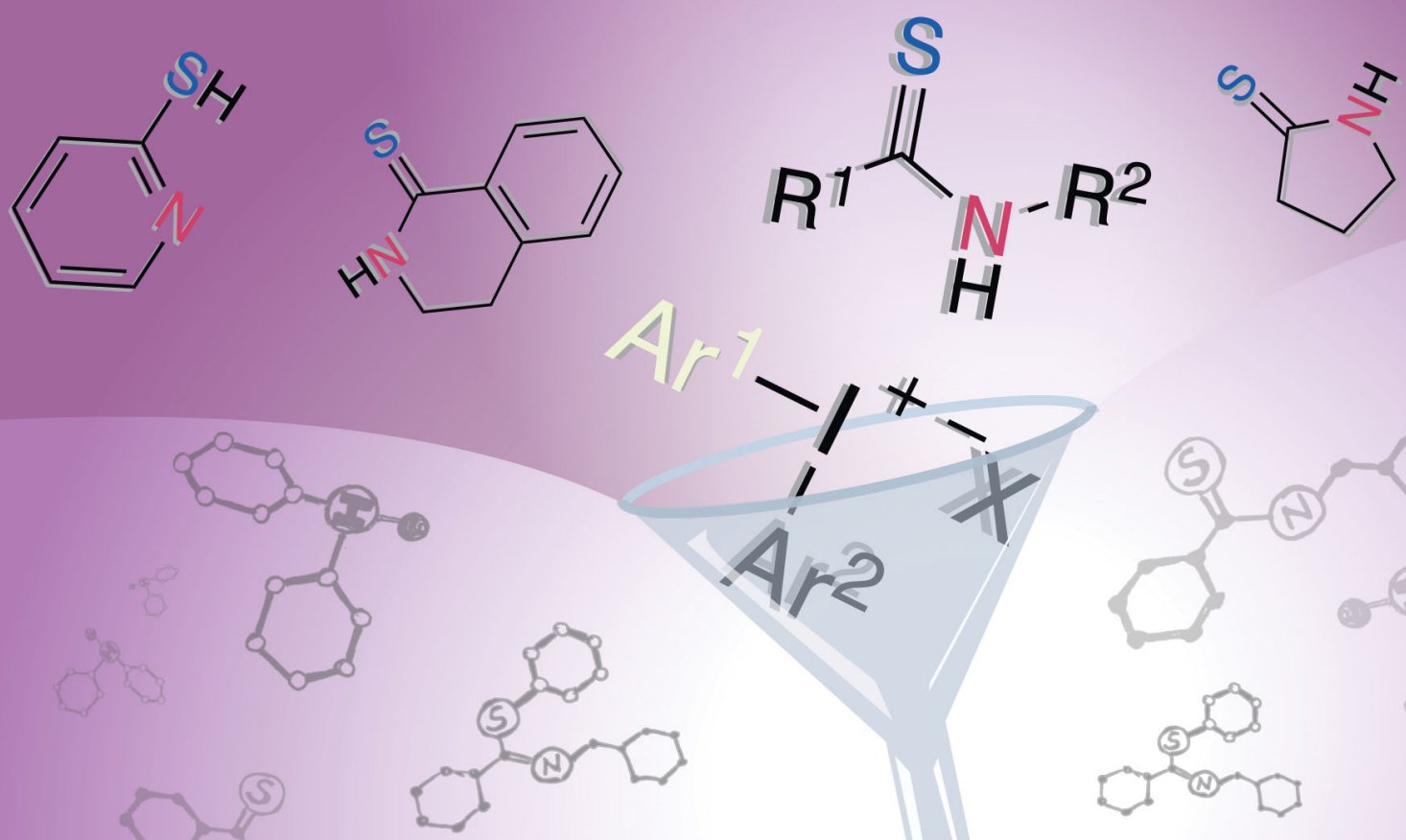

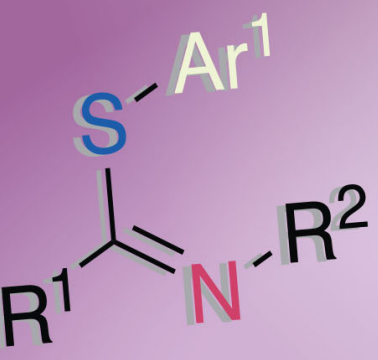
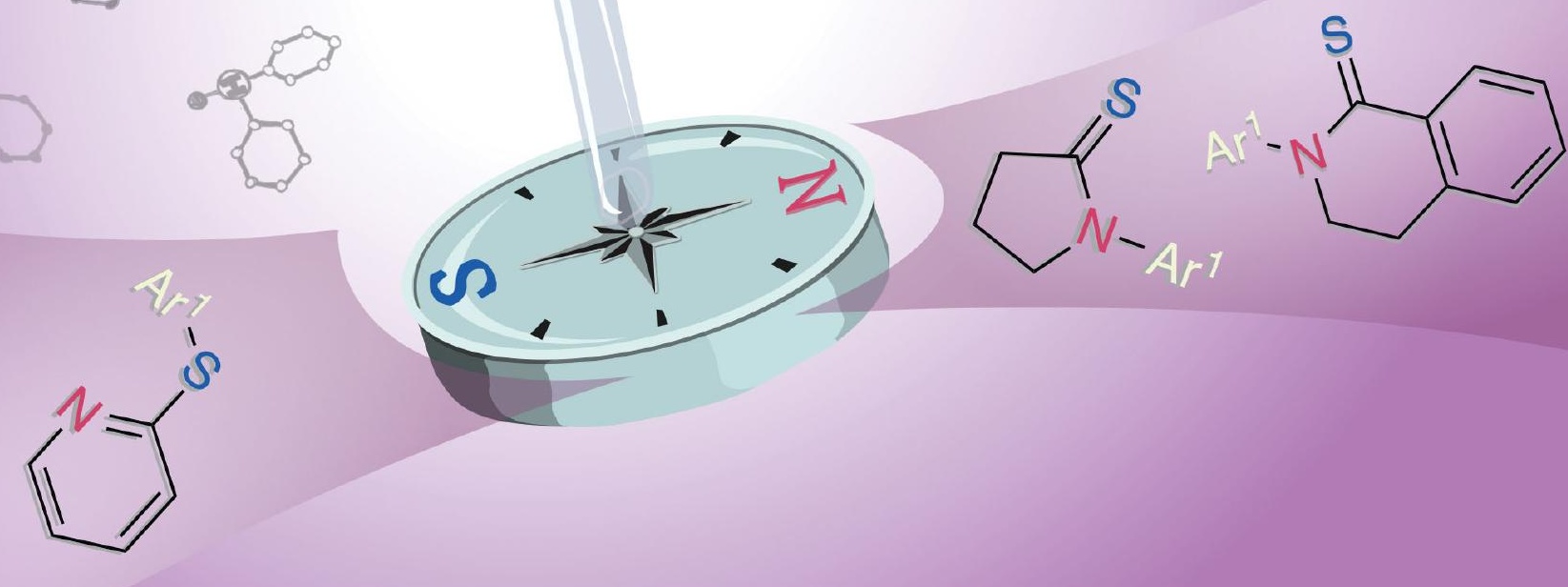

ISSN 1359-7345

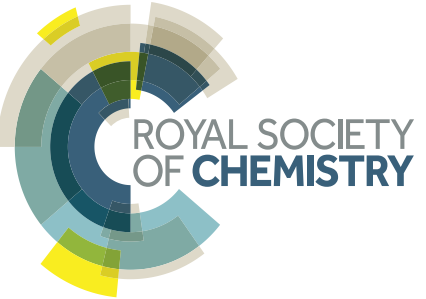


Check for updates

Cite this: Chem. Commun., 2018, 54,8810

Received 15th June 2018

Accepted 5th July 2018

DOI: $10.1039 / c 8 c c 04795 b$

rsc.li/chemcomm

\title{
Transition metal-free, chemoselective arylation of thioamides yielding aryl thioimidates or $\mathrm{N}$-aryl thioamides $\dagger$
}

\author{
Piret Villo, ${ }^{\text {ab }}$ Gabriella Kervefors ${ }^{a}$ and Berit Olofsson (D) *a
}

\begin{abstract}
Reactions of secondary thioamides with diaryliodonium salts under basic, transition metal-free conditions resulted in chemoselective $S$-arylation to provide aryl thioimidates in good to excellent yields. Equimolar amounts of thioamide, base and diaryliodonium salt were sufficient to obtain a diverse selection of products within short reaction times. Reactions with thiolactams delivered $\mathrm{N}$-arylated thioamides in good yield at room temperature.
\end{abstract}

Thioamides and their aryl thioimidate derivatives are important units in bioactive molecules, and in intermediates towards such compounds. ${ }^{1}$ The thioimidate moiety can also be found in heterocycles such as thiazoles and benzothiazoles, ${ }^{2}$ and in early stage solar absorbers. ${ }^{3}$ The aryl thioimidate scaffold has also been shown to regioselectively react with alkynes to give aryl thio azadienes. ${ }^{4}$ While alkylation of thioamides to access alkyl thioimidates is straightforward, the corresponding methodology to reach aryl thioimidates is much less developed. ${ }^{5}$ Conventional routes to access aryl thioimidates include reacting imidoyl chlorides, ketenimines or nitriles with thiophenols that already have an established $S$-aryl bond (Pinner synthesis). ${ }^{5 c, 6}$ A one-pot reaction between aryl thiol, hexamethyldisilazane and nitromethane gives related methaneimidothioate scaffolds. ${ }^{7}$ Formation of an aryl-sulfur bond in the synthesis of benzothiazoles can be achieved either via palladium-catalyzed $S$-arylation of thioacetamide with $o$-iodoanilines, followed by a cyclization; ${ }^{8}$ metalfree condensation of thioamides with 2-aminothiophenols, ${ }^{9}$ or an intramolecular cyclization of $o$-iodothiobenzanilide. ${ }^{10}$ Radical arylation of thioamides gave high yields of $S$-arylated products but could not be applied to thiolactams. ${ }^{11}$ To the best of our knowledge, the latter is the only report obtaining acyclic aryl thioimidates by direct $S$-arylation of thioamides. Diaryliodonium salts (diaryl$\lambda^{3}$-iodanes) are easily prepared hypervalent iodine reagents with

\footnotetext{
${ }^{a}$ Department of Organic Chemistry, Arrhenius Laboratory, Stockholm University, SE-106 91, Sweden.E-mail: berit.olofsson@su.se

${ }^{b}$ Institute of Technology, University of Tartu, Tartu 50 411, Estonia

$\dagger$ Electronic supplementary information (ESI) available: Experimental details, analytical data and NMR spectra of novel compounds. See DOI: 10.1039/c8cc04795b
}

low toxicity. ${ }^{12}$ They have frequently been employed to arylate heteroatom- or carbon nucleophiles, ${ }^{12,13}$ including the $S$-arylation of thioureas or closely related scaffolds under both metal-free, ${ }^{14}$ and copper-catalyzed conditions. ${ }^{15}$ While thioamides have never been arylated with diaryliodonium salts, iodine(III) reagents have been used to transfer alkenyl, alkynyl, trifluoromethyl, and nitrile functionalities to thioamides or similar compounds. ${ }^{16}$ Additionally, thioamides can be converted into benzothiazoles via oxidative arylation with bis(trifluoroacetoxyiodo)benzene. ${ }^{17}$ In our research line on hypervalent iodine chemistry, we have reported efficient, metal-free arylations of a range of heteroatom and carbon nucleophiles. ${ }^{18}$ Mechanistic aspects have been explored to expand the utility of these reagents in organic synthesis, also with focus on chemoselectivity using unsymmetric diaryliodonium salts. ${ }^{19}$ Reactions of nucleophiles with two possible arylation sites, e.g. enolates, amides, nitrite, oximes and quinolones, have proven highly selective towards $C$ - and $N$-arylation, respectively. ${ }^{18 b, c, 19 a, 20}$ Continuing on this track, we explored the arylation of thioamides, and herein describe the highly selective $S$-arylation of secondary thioamides with diaryliodonium salts under basic, transition metal-free conditions (Scheme 1).

Initial screenings revealed that the reaction of thioamide 1a with diphenyliodonium triflate (2a) delivered phenyl thioimidate $\mathbf{3 a}$ in $30-40 \%$ yield with a selection of organic and inorganic bases in toluene at room temperature. ${ }^{21}$ Recovered 1a and side-products from either hydrolysis ${ }^{22}$ of $3 a$ into the corresponding amide and thiol, or desulfurization, ${ }^{17,23}$ constituted the remaining mass. Remarkably, no $N$-arylated thioamide product was observed. Product 3a was isolated as an inseparable $Z: E$ isomeric mixture in $93: 7$ ratio, based on NMR analysis and literature data on similar compounds. ${ }^{7,24}$ This is in accordance with alkylations of thioamides, which have been reported to proceed with $S$-functionalization. ${ }^{25}$

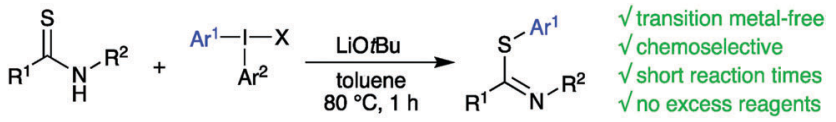

Scheme 1 Arylation of thioamides with diaryliodonium salts. 
Table 1 Selected optimization data

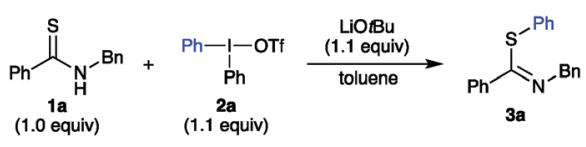

\begin{tabular}{lllll}
\hline Entry & Solvent quality & Temp $\left({ }^{\circ} \mathrm{C}\right)$ & Time $(\mathrm{h})$ & Yield $^{a}(\%)$ \\
\hline 1 & Anhydrous & $\mathrm{rt}$ & 16 & 42 \\
2 & Anhydrous & 40 & 16 & 61 \\
3 & Anhydrous & 80 & 16 & 71 \\
4 & Anhydrous & 80 & 1 & 75 \\
5 & Anhydrous under Ar & 80 & 1 & 79 \\
$\mathbf{6}$ & Degassed, anhydrous under Ar & $\mathbf{8 0}$ & $\mathbf{1}$ & $\mathbf{9 1}$ \\
${ }^{a}$ Isolated yields, major isomer of 3a shown. &
\end{tabular}

Based on these initial promising results, an extensive optimization was performed. ${ }^{21}$ A solvent screening with LiOtBu as base revealed that EtOAc, $i$ PrOAc and $\mathrm{CH}_{2} \mathrm{Cl}_{2}$ gave comparable yields to reactions in toluene. The reaction temperature had a great impact on the reaction outcome, and reactions at $80{ }^{\circ} \mathrm{C}$ allowed the reaction time to be decreased from overnight to one hour (Table 1, entries 1-4). While running the reaction under argon atmosphere only influenced the outcome marginally (entry 5), degassing the solvent enhanced the yield considerably (entry 6). A counterion effect for the iodonium salt was also observed, where diphenyliodonium salts with OTf, OTs and Br outperformed iodonium salts with $\mathrm{BF}_{4}, \mathrm{TFA}$ and $\mathrm{PF}_{6}{ }^{21}$

With the optimized conditions in hand, we looked into the scope of diaryliodonium salts with thioamide 1a (Scheme 2A). Symmetric and unsymmetric diaryliodonium salts were synthesized using efficient one-pot methodology, ${ }^{26}$ with phenyl, anisyl and trimethoxyphenyl (TMP) as "dummy" groups. The use of unsymmetric iodonium salts is often more atom efficient and cost effective, e.g. when highly functionalized or precious aryl groups are transferred. ${ }^{21}$ High chemoselectivity is crucial for this approach, i.e. selective transfer of only one of the aryl groups, ${ }^{19 b, d}$ and the arylation results with unsymmetric diaryliodonium salts proved superior to the corresponding symmetric salts in several $S$-arylations shown below. ${ }^{21}$ Electron deficient diaryliodonium salts generally behave well in heteroatom arylations, and the synthesis of $p$-CN product $\mathbf{3 b}$ indeed proceeded in excellent yield. Likewise, the $p-\mathrm{NO}_{2}$ product $3 \mathrm{c}$ was easily obtained, and surprisingly performed better in a non-degassed solvent. ${ }^{27}$

Further so, aryls with $p-\mathrm{OCF}_{3}$ (3d) and $p-\mathrm{CF}_{3}$ (3e) were delivered in good yields as well. Electron-withdrawing substituents in the meta- and ortho-positions were also tolerated, providing $m-\mathrm{CF}_{3}$ substituted 3f, with slightly lower $Z: E$ ratio than previously observed; and $o-\mathrm{F}$ and $o$-COOMe decorated $3 \mathbf{g}-\mathbf{3 h}$. Importantly, the introduction of aryl groups with a straightforward handle for further derivatization proved feasible, as exemplified by a $p-\mathrm{N}_{3}$ aryl moiety in $\mathbf{3} \mathbf{i}$ and halide-substituted products $\mathbf{3} \mathbf{j}$, 3k, for which unsymmetric iodonium salts proved more efficient than the corresponding symmetric salts. ${ }^{21}$ Arylations with electron donating diaryliodonium salts can be demanding, as competing reaction pathways tend to give product mixtures. ${ }^{19 c}$ Pleasingly, this $S$-arylation proved compatible with such iodonium salts, and alkyl-substituted products $\mathbf{3 1 - 3 0}$ were obtained in good yields,

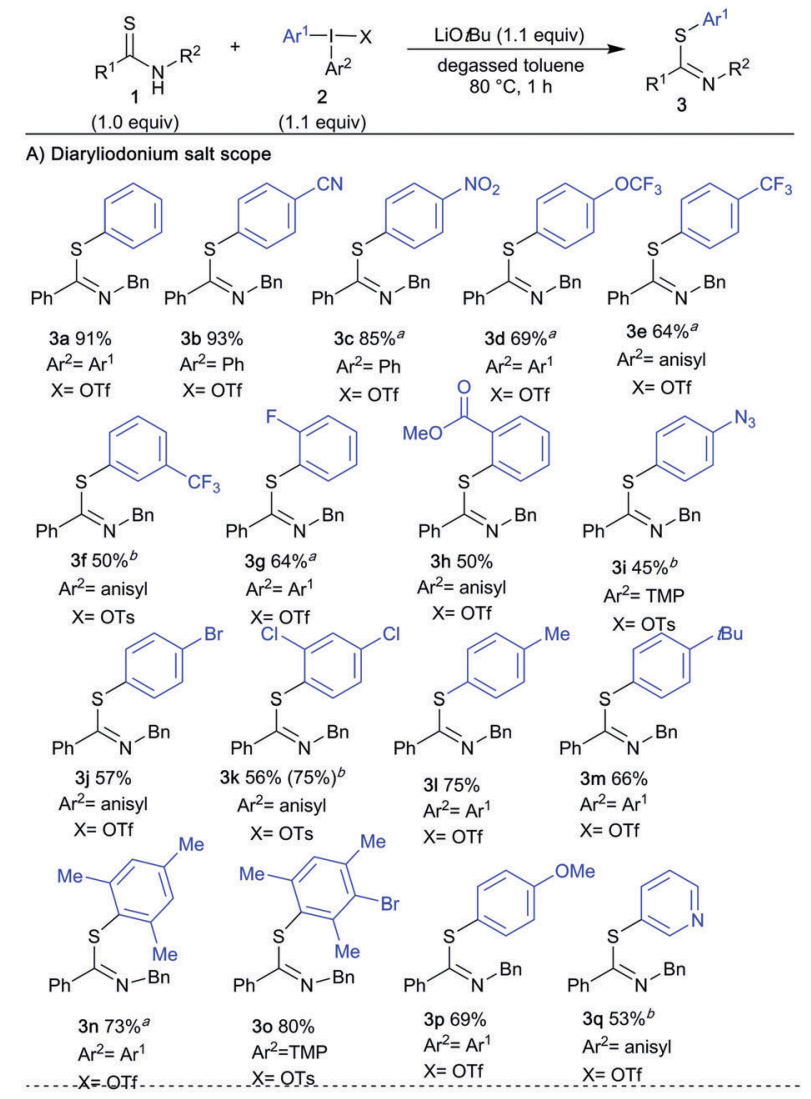

B) Thioamide scope
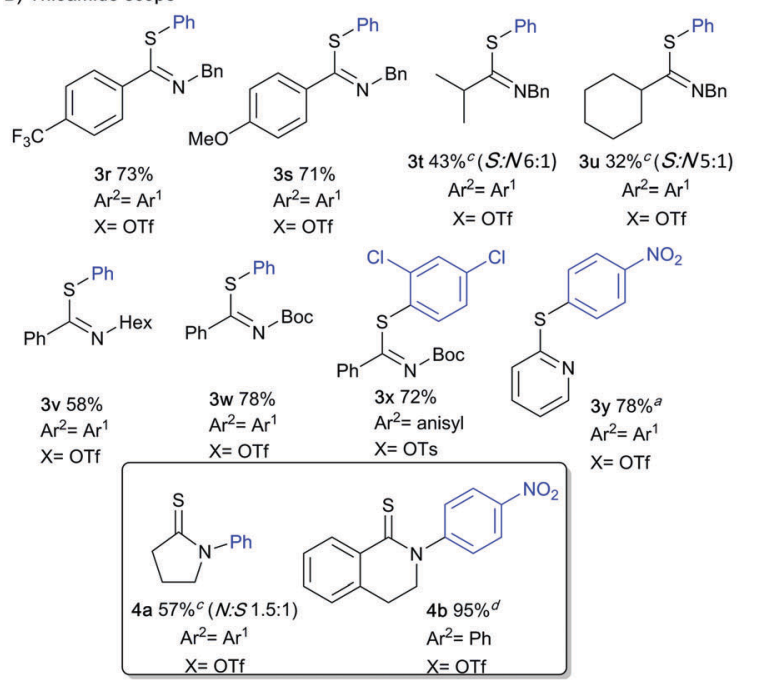

Scheme 2 Arylation scope with major isomer (Z) shown. $Z: E$ ratios $91: 9$ to $96: 4$, except $\mathbf{3 d}(89: 11), \mathbf{3 f}(88: 12), 3 \mathbf{h}(86: 14), 3 \mathbf{i}(90: 10), 30(86: 14)$, and $\mathbf{3 q}(87: 13)$. Only one isomer obtained of $\mathbf{3 w}-\mathbf{4 b}$. ${ }^{a}$ In non-degassed toluene. ${ }^{b}$ NMR yield. ${ }^{c}$ Combined yield. ${ }^{d}$ At rt for $16 \mathrm{~h}, 1.5$ equiv. base.

including the sterically congested 3n-3o. Furthermore, an anisyl group could easily be transferred (3p), and the synthesis of pyridyl product $\mathbf{3 q}$ was viable. Complete chemoselectivity was generally observed in the arylations, with minor amounts of dummy group transfer only in the synthesis of $3 \mathbf{j} .{ }^{21}$ The reaction was demonstrated to have a considerable orthoeffect $^{28}$ with high yields and complete chemoselectivity in 


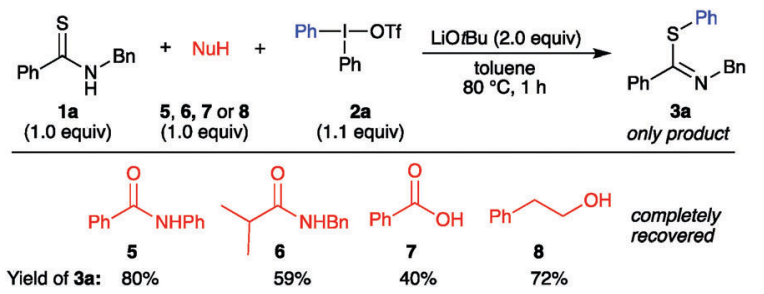

Scheme 3 Competition experiments.

the synthesis of $\mathbf{3 k}$ and $3 \mathbf{3 o}^{21}$ The scope of thioamide scaffolds was explored next (Scheme 2B). Both electron donating and withdrawing groups on the benzothioamide were well tolerated, delivering $3 \mathbf{r}$ and $3 \mathbf{s}$ in good yields. Contrary to the aryl thioamides, the arylation of alkylated thioamides resulted in $S$-arylated products 3t, $3 \mathbf{u}$ in moderate yield, along with a minor amount of $\mathrm{N}$-arylation. The $N$-benzyl group could be replaced by a hexyl group to deliver 3w. More importantly, an easily removable Boc group was also tolerated, delivering $S$-arylated products $\mathbf{3 w}$ and $\mathbf{3 x}$ in high yields. Interestingly, reactions with this substrate in the presence of the weaker base potassium carbonate only gave recovered starting material, despite the more acidic $\mathrm{NH}$ proton. ${ }^{21}$ Furthermore, the heteroaromatic substrate pyridine-2-thiol proved suitable for this transformation, providing $3 \mathbf{y}$ in $78 \%$ yield. Cyclic thioamides, on the other hand, acted differently under the optimized conditions. Pyrrolidine-2-thione gave a mixture of $N$ - and $S$-arylated products (4a, $N: S$ ratio $1.5: 1) .{ }^{21}$ Interestingly, the synthesis of $\mathbf{4 b}$ proceeded in excellent yield and complete $N$-selectivity at room temperature. This product class could give access to $N$-arylated amides after a one-step desulfurization. ${ }^{23 b, 29}$ Competition experiments were performed to evaluate the $S$-arylation in the presence of $O$ - and $N$-nucleophiles that have been reported to undergo arylation with diaryliodonium salts under metal-free conditions. ${ }^{18 c, 30}$ Hence, reactions of thioamide $1 \mathrm{a}$ and $\mathrm{Ph}_{2}$ IOTf were performed in the presence of amide 5 or 6 , benzoic acid (7), or alcohol 8, and 2 equiv of base, to allow deprotonation of both nucleophiles (Scheme 3). The reactions proved to be completely chemoselective, with arylation of only thioamide $\mathbf{1 a}$ in all of the cases. $S$-Arylated thioimidate $\mathbf{3 a}$ was isolated in yields of $40-80 \%$, with complete recovery of the competing nucleophile in all reactions.

Preliminary mechanistic investigations revealed that addition of aryne or radical scavengers (piperidine and 1,1-diphenylethylene, respectively) had negligible effect on the reaction outcome. ${ }^{21}$ Hence both an aryne pathway and a radical mechanism can be excluded. Based on previous experimental and mechanistic studies of enolates, amides and nitrite, ${ }^{18 b, c, 19 a}$ we propose that the reaction proceeds by deprotonation and ligand exchange to provide T-shaped intermediate A and/or B (Scheme 4). Ligand coupling in $I-N$ intermediate $\mathbf{A}$ to form the $S$-arylated thioimidate $\mathbf{3}$ would proceed via a [2,3] rearrangement, whereas $I-S$ intermediate $\mathbf{B}$ would undergo a [1,2] rearrangement to yield $\mathbf{3}$. Alternatively, intermediates $\mathbf{A}$ and B could yield $\mathrm{N}$-aryl thioamide 4 through $[1,2]$ and $[2,3]$ rearrangement, respectively.

The $S$-arylation selectivity observed for all acyclic thioamides, as well as the aromatic thioamide, can be rationalized by efficient conjugation of the nitrogen lone pair in the thioamide
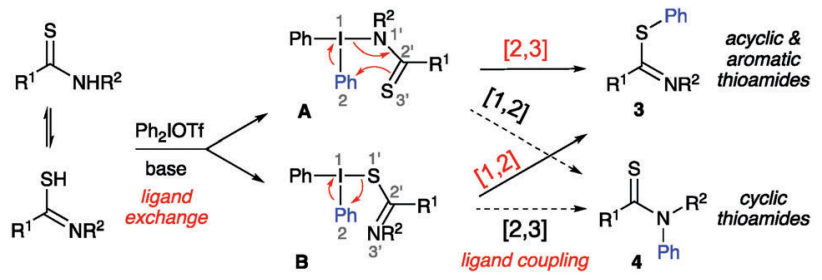

Scheme 4 Proposed mechanism for $S$ - and $N$-arylation.

moiety, making the sulfur lone pairs most nucleophilic. The observed $\mathrm{N}$-selectivity in arylation of thiolactams could be caused by less efficient conjugation due to cyclic constraints, making nitrogen a better nucleophile. While early literature proposed a rearrangement from $S$-arylated to $N$-arylated products, ${ }^{31}$ we observed constant $N / S$-arylation ratios throughout the reactions, making this mechanism unlikely. ${ }^{21}$

To conclude, we have developed a transition metal-free arylation of thioamides with diaryliodonium salts under basic conditions. Complete selectivity in favor of $S$-arylated products was observed with acyclic and aromatic thioamides, whereas thiolactams preferably were $N$-arylated. A wide scope of functional groups are tolerated in both thioamides and diaryliodonium salts. Furthermore, sterically congested aryl groups were transferred in high yield, and a considerable ortho-effect was observed. Efficient use of unsymmetric diaryliodonium salts have been demonstrated, with excellent chemoselectivity and improved yields compared to the corresponding symmetric reagents.

The Estonian Research Council (MOBTP59, PUTJD114) and the Swedish Research Council (2015-04404) are kindly acknowledged for financial support.

\section{Conflicts of interest}

There are no conflicts to declare.

\section{Notes and references}

1 Recent applications of thioamide and thioimidate scaffolds: (a) S. Julie, R. Patrick and T. Arnaud, Angew. Chem., Int. Ed., 2010, 49, 577-580; (b) W. Zhang, J. Li, L.-W. Liu, K.-R. Wang, J.-J. Song, J.-X. Yan, Z.-Y. Li, B.-Z. Zhang and R. Wang, Peptides, 2010, 31, 1832-1838; (c) H. Verma, B. Khatri, S. Chakraborti and J. Chatterjee, Chem. Sci., 2018, 9, 2443-2451; (d) S. Coyne, C. Chizzali, M. N. A. Khalil, A. Litomska, K. Richter, L. Beerhues and C. Hertweck, Angew. Chem., Int. Ed., 2013, 52, 10564-10568; (e) O. V. Solod, K. N. Zelenin and V. V. Pinson, Chem. Heterocycl. Compd., 1996, 32, 1-11; $(f)$ T. S. Jagodziński, Chem. Rev., 2003, 103, 197-228.

2 Reviews on synthesis of heterocycles: (a) M. Witalewska, A. WronaPiotrowicz, A. Makal and J. Zakrzewski, J. Org. Chem., 2018, 83, 1933-1939; (b) M. Koketsu and H. Ishihara, Curr. Org. Synth., 2007, 4, 15-29; (c) W.-S. Guo, L.-R. Wen and M. Li, Org. Biomol. Chem., 2015, 13, 1942-1953.

3 A. L. Catherall, S. Harris, M. S. Hill, A. L. Johnson and M. F. Mahon, Cryst. Growth Des., 2017, 17, 5544-5551.

4 Y. Minami, H. Kuniyasu, A. Sanagawa and N. Kambe, Org. Lett., 2010, 12, 3744-3747.

5 Reviews on thioimidate synthesis: (a) R. Roger and D. G. Neilson, Chem. Rev., 1961, 61, 179-211; (b) W. Kantlehner, in Comprehensive Organic Synthesis, ed. I. Fleming, Pergamon, Oxford, 1991, pp. 485-599; (c) N. Nakajima and M. Ubukata, Sci. Synth., 2005, 22, 361-366.

6 A. N. Kolontsova, M. N. Ivantsova, M. I. Tokareva and M. A. Mironov, Mol. Diversity, 2010, 14, 543-550. 
7 K. Krzysztof and H. Grzegorz, Eur. J. Org. Chem., 2016, 4577-4585.

8 K. Takagi, T. Iwachido and N. Hayama, Chem. Lett., 1987, 839-840.

9 K. R. Nivalkar and S. H. Mashraqui, Synth. Commun., 1996, 26, 3535-3542.

10 W. R. Bowman, H. Heaney and P. H. G. Smith, Tetrahedron Lett., 1982, 23, 5093-5096.

11 (a) I. I. Kandror and I. O. Bragina, Izv. Akad. Nauk SSSR, Ser. Khim., 1982, 2121-2125; (b) I. I. Kandror, B. V. Kopylova and R. K. Freidlina, Sulfur Rep., 1984, 3, 289-316.

12 E. A. Merritt and B. Olofsson, Angew. Chem., Int. Ed., 2009, 48, 9052-9070.

13 (a) K. Aradi, B. L. Tóth, G. L. Tolnai and Z. Novák, Synlett, 2016, 1456-1485; (b) B. Olofsson, Top. Curr. Chem., 2016, 373, 135-166; (c) A. Yoshimura and V. V. Zhdankin, Chem. Rev., 2016, 116, 3328-3435.

14 (a) Z. Bianxiang, K. Yongqiang, Y. Lihua and C. Xia, ChemistrySelect, 2016, 1, 1529-1532; (b) R. Sathunuru, H. Zhang, C. W. Rees and E. Biehl, Heterocycles, 2005, 65, 1615-1627; (c) R. Sathunuru and E. Biehl, ARKIVOC, 2004, 51-60; (d) S. Bátori and A. Messmer, J. Heterocycl. Chem., 1988, 25, 437-444; (e) Z. Chen, Y. Jin and P. J. Stang, J. Org. Chem., 1987, 52, 4117-4118; The arylation of pyridine 2-thiol is reported: $(f)$ A. M. Wagner and M. S. Sanford, J. Org. Chem., 2014, 79, 2263-2267.

15 H. Zhu, X. Liu, Y. Cheng, H.-Y. Peng, Y.-S. Li and Z.-B. Dong, Synthesis, 2018, 2247-2254.

16 Selected references on functionalization of thioamides with iodine(III) reagents: (a) M. Ochiai, S. Yamamoto, T. Suefuji and D.-W. Chen, Org. Lett., 2001, 3, 2753-2756; (b) M. Ochiai and S. Yamamoto, Chem. Commun., 2002, 2802-2803; (c) P. Wipf and S. Venkatraman, J. Org. Chem., 1996, 61, 8004-8005; (d) K. Miyamoto, Y. Nishi and M. Ochiai, Angew. Chem., Int. Ed., 2005, 44, 6896-6899; Selected references on functionalization of similar substrates with iodine(III) reagents: $(e)$ R. Frei and J. Waser, J. Am. Chem. Soc., 2013, 135, 9620-9623; $(f)$ S. P. Spyroudis, Liebigs Ann. Chem., 1986, 947-951; $(g)$ E. D. Matveeva, T. A. Podrugina, A. S. Pavlova, A. V. Mironov and N. S. Zefirov, Russ. Chem. Bull., 2008, 57, 400-405; (h) W. Zhang, J. Zhu and J. Hu, Tetrahedron Lett., 2008, 49, 5006-5008.

17 N. K. Downer-Riley and Y. A. Jackson, Tetrahedron, 2008, 64, 7741-7744.

18 (a) G. L. Tolnai, U. J. Nilsson and B. Olofsson, Angew. Chem., Int. Ed., 2016, 55, 11226-11230; (b) M. Reitti, P. Villo and B. Olofsson, Angew. Chem., Int. Ed., 2016, 55, 8928-8932; (c) F. Tinnis, E. Stridfeldt, H. Lundberg, H. Adolfsson and B. Olofsson, Org. Lett., 2015, 17,
2688-2691; (d) C. Dey, E. Lindstedt and B. Olofsson, Org. Lett., 2015, $17,4554-4557$.

19 (a) P.-O. Norrby, T. B. Petersen, M. Bielawski and B. Olofsson, Chem. - Eur. J., 2010, 16, 8251-8254; (b) J. Malmgren, S. Santoro, N. Jalalian, F. Himo and B. Olofsson, Chem. - Eur. J., 2013, 19, 10334-10342; (c) E. Stridfeldt, E. Lindstedt, M. Reitti, J. Blid, P.-O. Norrby and B. Olofsson, Chem. - Eur. J., 2017, 13249-13258; (d) D. R. Stuart, Chem. - Eur. J., 2017, 23, 15852-15863; (e) H. Pinto de Magalhães, H. P. Lüthi and A. Togni, Org. Lett., 2012, 14, 3830-3833.

20 (a) X.-P. Ma, W.-M. Shi, X.-L. Mo, X.-H. Li, L.-G. Li, C.-X. Pan, B. Chen, G.-F. Su and D.-L. Mo, J. Org. Chem., 2015, 80, 10098-10107; (b) M. K. Mehra, M. P. Tantak, V. Arun, I. Kumar and D. Kumar, Org. Biomol. Chem., 2017, 15, 4956-4961.

21 See the ESI $\dagger$ for details.

22 (a) W. Walter and J. Krohn, Chem. Ber., 1969, 102, 3786-3794; (b) R. K. Chaturvedi, A. E. MacMahon and G. L. Schmir, J. Am. Chem. Soc., 1967, 89, 6984-6993.

23 (a) S. Nobutaka, S. Kaniti, W. Satoshi, T. Noriyuki and I. Yasuji, Bull. Chem. Soc. Jpn., 1982, 55, 3351-3352; (b) A. K. Yadav, V. P. Srivastava and L. D. S. Yadav, New J. Chem., 2013, 37, 4119-4124.

24 Z. Guan, M. Nieger and A. Schmidt, Eur. J. Org. Chem., 2015, $4710-4719$.

25 Y. Karibe, H. Kusama and N. Iwasawa, Angew. Chem., Int. Ed., 2012, 51, 6214-6218.

26 (a) E. Lindstedt, M. Reitti and B. Olofsson, J. Org. Chem., 2017, 82, 11909-11914; (b) M. Zhu, N. Jalalian and B. Olofsson, Synlett, 2008, 592-596; (c) M. Bielawski, M. Zhu and B. Olofsson, Adv. Synth. Catal., 2007, 349, 2610-2618.

27 A preliminary substrate scope was performed without degassing the solvent, as this effect was discovered late in the project. See the ESI $\dagger$ for details.

28 Y. Yamada and M. Okawara, Bull. Chem. Soc. Jpn., 1972, 45, 1860-1863.

29 I. Mohammadpoor-Baltork, M. M. Sadeghi and K. Esmayilpour, Phosphorus, Sulfur Silicon Relat. Elem., 2003, 178, 61-65.

30 (a) T. B. Petersen, R. Khan and B. Olofsson, Org. Lett., 2011, 13, 3462-3465; (b) R. Ghosh, E. Lindstedt, N. Jalalian and B. Olofsson, ChemistryOpen, 2014, 3, 54-57.

31 A. Varvoglis, Synthesis, 1984, 709-726. 